\title{
O PAPEL DA JUSTIÇA TRANSICIONAL NA CONSTRUÇÃO DA DEMOCRACIA NA ÁFRICA DO SUL
}

\author{
Jaqueline Richard*
}

\section{RESUMO}

O presente artigo busca compreender o processo e institucionalização de justiça a respeito dos Direitos Humanos após o final do regime de apartheid na África do Sul. A África do Sul é um país que viveu sob um regime segregacionista por mais de quatro décadas, quando os negros foram legalmente excluídos, tiveram seus direitos de cidadãos suprimidos e serviram apenas como força de trabalho. Hoje em dia os negros sul-africanos conseguiram retomar seu poder como cidadãos políticos (sufrágio universal) e fazem parte de um mercado de trabalho qualificado e amplo.

Palavras-chave: Justiça Transicional; Segregação Racial; Violações dos Direitos Humanos;

\begin{abstract}
The aim of this article is to emphasize the transitional justice ands the institutionalization of justice, as well as human rights respect to the citizenship in South Africa, after the apartheid. South Africa presented a large regime of segregation, placing the black population into exclusion. Nowadays the blacks are trying to get back their legal rights and have been trained to be inserted into formal jobs.
\end{abstract}

Key-words: transitional justice, race segregation, violation of human rights.

\section{Introdução}

O presente artigo busca compreender o processo e institucionalização de justiça a respeito dos Direitos Humanos após o final do regime de apartheid na África do Sul.

A África do Sul é um país que viveu sob um regime segregacionista por mais de quatro décadas. Nesse sentido, os negros, que representam a maioria da população nessa região, foram legalmente excluídos, tiveram seus direitos de cidadãos suprimidos e serviram apenas como força de trabalho. Porém, hoje os negros sul-africanos conseguiram retomar seu poder como cidadãos políticos (sufrágio universal) e fazem parte de um mercado de trabalho qualificado e amplo. No entanto, a nova organização sul-africana ainda não conseguiu absorver todas as mudanças do antigo regime, pois esse trouxe muitas consequiências, principalmente no que concerne ao campo dos Direitos Humanos.

Desde a sua colonização e durante todo o período do apartheid, a África do Sul foi marcada por uma política de violência repleta de violações dos Direitos Humanos. Muitos negros foram torturados, assassinados, massacrados e discriminados. 


\begin{abstract}
* Bacharel em Relações Internacionais pelo UniCEUB. O presente ensaio é resultado da monografia final de curso sob orientação do Prof. Tarciso Dal Maso Jardim.

Nesse sentido, após o término desse período e a emergência de um governo democrático, viu-se a necessidade de restaurar a relação entre a população negra e o Estado que legitimava essa força de ação, implementando uma forma de justiça contra todos esses abusos. A preocupação maior era fazer com que os abusos que foram cometidos no passado não ocorressem novamente, haja vista que o governo africâner, mesmo após a primeira eleição democrática não racial realizada em 1994, ainda detinha um poder relevante, principalmente sobre as forças de segurança. Diante disso, buscou-se um método para lidar com os responsáveis pe ${ }^{1}$ las violações de Direitos Humanos. Em 1995, foi estabelecido pelo Government of National Unity a Comissão de Verdade e Reconciliação. Essa seria uma tentativa não judicial de buscar a verdade e demonstrar à sociedade que os violadores reconhecem o que fizeram e não irão fazer novamente.
\end{abstract}

\title{
A JUSTIÇA TRANSICIONAL
}

Recentemente, vários movimentos contra regimes caracterizados por violações de Direitos Humanos têm ganhado força. Países principalmente da América Latina, da África e do Leste Europeu têm passado por processos de transição política nas últimas décadas.

Além das mudanças necessárias para alcançar plenamente o regime democrático, esses países enfrentam desafios principalmente no que concerne ao desenvolvimento de novas políticas para tratar de assuntos acerca da reconstrução moral da sociedade.

Esses regimes repressivos são caracterizados por massivas violações de Direitos Humanos. Diante disso, uma das maiores preocupações do Estado sucessor é provar, perante a sociedade, que os violadores que cometeram essas atrocidades no passado serão de alguma forma punidas e lhes assegurar que essas violações não irão acontecer novamente.

Por conseqüência, foi desenvolvido um novo conceito de justiça. A justiça transicional se refere como as sociedades lidam com atrocidades passadas cometidas por uma ordem repressiva ou um conflito armado, como elas superam as divisões ou procuram reconciliação, e como elas criam um sistema de justiça que previna futuras violações contra os Direitos Humanos. ${ }^{2}$

A importância de se discutir a justiça transicional é que essa se constitui uma forma de justiça alternativa que foge da prerrogativa tradicional, em que o Estado é responsável por investigar e condenar os culpados. Nesse caso o Estado é considerado o maior violador. Sendo assim, buscam-se formas diferentes de investigar e condenar aqueles que cometeram algum erro no passado.

Um de seus principais instrumentos são as Comissões de Verdade. Essas são instituições de caráter temporário que podem ser estabelecidas por um parlamento, como na África do Sul, por um decreto do Presidente, como no Chile ou até mesmo por uma Organização Internacional, como foi o caso da Comissão instaurada em El Salvador que era tutelada pela Organização das Nações Unidas. Seu campo de ação tange várias áreas.

\footnotetext{
${ }^{2}$ CALL,Charles T. Is Transitional Justice Really Just? Journaul of World Affairs, Volume 11. 2004, p. 101
} 
Algumas cuidam especificamente de assassinatos, torturas, seqüestros e desaparecimentos; outras analisam todos os tipos abusos.

Uma inovação interessante desse processo de julgamento, é que ele leva em consideração o consenso da sociedade. O conhecimento público a respeito do passado é produzido através de um processo de representação envolvendo os violadores, as vítimas e a sociedade, construindo a investigação histórica com base no consenso popular. ${ }^{3}$

Geralmente as Comissões são conectadas diretamente aos órgãos judiciários dos Estados, fato que as ajuda na criação de leis de anistias e leis referentes à condenação.

Algumas Comissões têm o poder de investigar, intimar e condenar, porém outras possuem o poder judicial limitado, como no caso da Comissão de Justiça e Reconciliação instaurada na África do Sul em 1995. ${ }^{4}$ Mas uma característica todas elas têm em comum: as Comissões de Verdade devem ser sempre imparciais. Entende-se por imparcialidade que as Comissões de Verdade não são tendenciosas para nenhum tipo de governo, ou seja, elas não se deixam influenciar por nenhum tipo de política.

As primeiras fontes de provas da Comissão são as próprias vítimas. Elas são as primeiras a serem ouvidas no processo de investigação, haja vista que foram elas próprias que sofreram com as violações. O depoimento da vítima e de outras testemunhas é primeiramente reconstruído por um membro da Comissão em uma história única da repressão do Estado. ${ }^{5}$ A partir desse ponto começa-se a construir o relatório.

O relatório da Comissão é entregue ao final de sua ação. Nele deve conter a história do caso, os nomes dos violadores condenados e as recomendações de reparações a serem feitas à sociedade.

A primeira Comissão de Verdade foi instaurada em 1974 na Uganda. Porém essa Comissão não obteve resultados muito satisfatórios, pois era muito geral, ou seja, não tinha detalhes dos casos individuais. Depois dessa, muitas outras foram formadas evoluindo e trazendo resultados mais aplicáveis para a sociedade. Dentro de muitas formadas na década de 80 e 90 destaca-se a Comissão da Argentina, da África do Sul, do Chile, da Alemanha, de El Salvador, da Guatemala e do Peru. Mais recentemente, foram formadas Comissões entre outros países, na Coréia do Sul, no Líbano, na Serra Leoa, no Timor Leste, na Somália, e na Iugoslávia.

É interessante ressaltar que essas Comissões não trabalham sozinhas. Existem outros meios não oficiais que ajudam seus trabalhos. A participação de Organizações não Governamentais já influenciou relativamente no andamento de várias Comissões. Muitos relatórios já foram produzidos por Organizações como a Anistia Internacional e muitos países tiveram a participação de ONG's nacionais, tanto na elaboração do relatório quanto na publicação de livros a respeito do assunto. Ademais, em muitos lugares os parentes de vítimas desaparecidas ou mortas formam comitês para ajudar nas investigações e prestar solidariedade para outras vítimas.

\section{A COMISSÃO DE VERDADE E RECONCILIAÇÃO DA ÁFRICA DO SUL}

\footnotetext{
${ }^{3}$ RUTI, G. Teitel. Transitional Justice. New York: Oxford University Press, 2000. p. 81

${ }^{4}$ Idem.

${ }^{5}$ Ibidem. p. 82.
} 
Após o final do regime de apartheid, o Estado sul-africano se viu pressionado para estabelecer um método para lidar com todas as violações de Direitos Humanos cometidas no passado. A sociedade civil deveria ser moralmente reconstruída, com base em princípios democráticos amparados em um novo conceito de nação única. Para que o legado da segregação racial, assim como todas as violações cometidas desde sua colonização fossem superadas, seria necessário que toda a verdade sobre os atos cometidos fosse revelada e que os culpados a assumissem perante toda a sociedade. A partir disso seria viável o estabelecimento da memória coletiva, a fim de reconstruir uma nova comunidade.

No final dos anos 80 e inícios dos anos 90, movimentos de libertação apoiados pela maioria dos cidadãos sul-africanos desafiaram o Governo. No entanto, essas mobilizações, apesar de terem sido muito significativas, foram contidas muitas vezes pelas forças de segurança. Contudo, essas reivindicações ganharam o apoio da maioria da comunidade internacional que clamavam por democracia na África do Sul. Como resultado disso, o país foi submetido a uma intensa campanha de isolamento, consistindo em sanções econômicas, assim como boicotes atléticos, acadêmicos, científicos e culturais. Esse isolamento afetou diretamente toda a vida dos sul-africanos, o que acabou pressionando o Governo a mudar suas políticas e ceder, tanto à pressão interna quanto da comunidade internacional. Esses fatos acabaram forçando os dois maiores partidos sul-africanos a negociarem. $\mathrm{O}$ governo percebeu que não podia ignorar a resistência dos movimentos internos, assim como desconsiderar a opinião internacional. Concomitantemente, os movimentos de libertação reconheceram que não conseguiram manter sua campanha militar durante muito tempo, haja vista a relevante resistência do governo. Assim sendo, os dois lados concordaram que a única solução viável para a África do Sul seria a institucionalização de uma nova ordem. ${ }^{6}$

Um dos primeiros passos para construção de uma nova África do Sul deu-se após a vitória do partido de Nelson Mandela, o Congresso Nacional Africano (CNA), na primeira eleição multirracial, em 1994. O novo parlamento sancionou em 1995 o "The Promotion of National Unity and Reconciliation Act" (TRC Act), que permitia o estabelecimento de uma Comissão de Verdade e Reconciliação que iria auxiliar o novo governo a revelar a verdade sobro todos os abusos de Direitos Humanos cometidos no passado, assim como ajudaria na restauração das vítimas e na reconstrução da nova sociedade única e democrática. ${ }^{7}$ A Comissão presidida pelo bispo Desmond Tutu iniciou suas investigações em Abril de 1996 e teve seus trabalhos finalizados em Outubro de 1998, com a publicação de seu relatório final.

Comparando com as recentes comissões instauradas principalmente na América do Sul, a Comissão de Verdade e Reconciliação da África do Sul serve como exemplo de instituição inovadora e bem sucedida para os países que estão em fase de transição. Esse sucesso pode ser justificado por vários fatores.

O primeiro e mais relevante é o fato de ter sido a primeira Comissão que inclui o conceito de anistia individual, em que tanto as vítimas quanto os violadores eram ouvidos em audiências públicas. Muitas outras Comissões, como a da Argentina, do Brasil e do

\footnotetext{
${ }^{6} \mathrm{ZYL}$, Paul Van. Dilemmas of Transitional Justice: The case of South Africa's Truth and Reconciliation Commission. Journal of Internations Affairs, Sprig 1999, 52, $\mathrm{n}^{\circ} 2$. The Trustees of Columbia University in the City of New York. p. 649.

${ }^{7}$ A criação da Comissão de Verdade e Reconciliação pode ser considerado um passo relevante no aspecto democrático da África do Sul, na medida que seu estabelecimento só foi autorizado depois de um amplo debate público com relação aos seus objetivos e seus procedimentos.
} 
Chile, utilizaram somente o princípio da anistia coletiva para julgar seus casos. Um outro fator diz respeito a figura de um líder carismático que incorporava a verdade e reconciliação em sua própria vida. Nelson Mandela destacava a necessidade de tratar de abusos cometidos no passado associado sempre com a idéia do perdão. Um terceiro ponto favorável diz respeito à existência de uma sociedade civil forte. O fato da maioria dos sulafricanos terem sido excluídos do processo parlamentar e governamental acabou incentivando a população a se organizar e desenvolver Organizações não Governamentais que ajudavam a Comissão. Algumas eram voltadas para assuntos legais, outras para educação, religião e outras ainda organizadas para cuidar das vítimas do apartheid. Como exemplo pode-se destacar a Justice in Transition. Essa ONG criou várias oportunidades de conferências e workshops, onde se debatiam os papéis da Comissão, destacando seu forte processo democrático. E por fim, ao apoio da comunidade internacional. Governos de outros países, assim como instituições, organizações e até mesmo indivíduos ajudavam com contribuições financeira para ajudar as vítimas na reabilitação e reparação através do President's Fund. ${ }^{8}$

Uma das principais dificuldades encontrada pela Comissão era fazer com que o antigo governo, que ainda detinha considerável poder, principalmente no campo militar, seguisse suas recomendações. Essas recomendações tangiam principalmente questões relacionadas a maneiras de reparar as vítimas e a justificar moralmente o processo de anistia.

Os principais objetivos da Comissão eram: estabelecer de acordo com os princípios de direito internacional e da Constituição um quadro completo de todas as violações de Direitos Humanos ocorridas no passado na África do Sul, no período compreendido entre $1^{\circ}$ de março de 1960 até 5 de dezembro de 1993, assim como seus antecedentes e circunstâncias, de modo a alcançar a reconciliação nacional; conceder informações e evidências que tornariam possível a identificação das vítimas pelo nome; recomendar maneiras de reparação de forma a restaurar a dignidade humana e civil das vítimas; receber pedido de anistia e indenização nos termos de revelação, e ao mesmo tempo fazer recomendações ao Presidente; preparar um relatório contendo todas as provas encontradas nas investigações e recomendar maneiras legais e administrativas para prevenir futuras violações de Direitos Humanos. Para isso, a Comissão contava com três comitês que a auxiliavam em todo o processo.

O Comitê de Anistia incluía membros da Comissão de Verdade e Reconciliação e profissionais legais. Sua maior tarefa era considerar a aplicação da anistia. Existem duas condições básicas para concessão de anistia. Primeiro o crime deve ser encaixado na definição de atos associados com objetivos políticos contidos do "TRC Act" e deve haver revelação plena por parte do violador. Uma vez a pessoa eleita para anistia, o Comitê deveria considerar suas motivações, assim como o contexto e a natureza do ato e depois encaminhar o acusado a uma audiência pública. O "TRC Act" especifica que pessoas que agiram com intuito de ganho pessoal não podem ser anistiadas, exceto se essas pessoas receberam dinheiro ou algo de valor para ser um informante. Uma vez concedida a anistia,

\footnotetext{
${ }^{8}$ BORAINE, Alex. A Country Unmasked: Inside South Africa's Truth and Reconciliation Commission. Oxford University Press. 2000. Cap. VIII.
} 
o nome do acusado e as informações a respeito do seu ato são publicadas no Government Gazzete, a publicação oficial do Governo.'

O Comitê de Violações de Direitos Humanos tinha o objetivo de coletar informações das vítimas tentando estabelecer um quadro completo dos abusos de Direitos Humanos. O Comitê tinha que descobrir se cada testemunha podia ou não ser declarada oficialmente vítima de acordo com a definição contida no "TRC Act". Nomes e informações relevantes sobre as vítimas eram encaminhadas ao Comitê de Reparação e Reabilitação. $^{10}$

O Comitê de Reparação e Reabilitação é o órgão reparador. Seus membros são essencialmente médicos e profissionais especializados em saúde mental. Pessoas encontradas pelo Comitê de Violações de Direitos Humanos, sejam vítimas ou seus familiares, utilizaram esse Comitê para reparação. Depois de considerar todas aplicações o Comitê de Reparação e Reabilitação envia recomendações políticas ao Presidente, com referência a como restaurar a dignidade civil e humana das vítimas. ${ }^{11}$

Com a ajuda desses Comitês tenta-se descobrir a verdade. O primeiro passo era ouvir as vítimas testemunhando a respeito dos abusos sofridos. O Comitê de Violações de Direitos Humanos tem mais de 120 locais para audiência espalhados pela África do Sul, onde aproximadamente 4000 vítimas testemunharam. A Comissão também direciona a responsabilidade pelos abusos de Direitos Humanos dentro de uma perspectiva mais ampla, examinando os papéis exercidos por vários profissionais e instituições que poderiam ter facilitado esses abusos. Por exemplo, ouvindo o corpo médico e os profissionais que trabalhavam nessa área durante o regime do apartheid, procurava-se focalizar em assuntos relacionados a códigos profissionais de conduta. Ademais, Comissão supervisiona aproximadamente 22.000 relatórios das vítimas que sofreram com violações de Direitos Humanos. Seu trabalho, junto com esses Comitês, ajudou a revelar o verdadeiro motivo da morte e desaparecimento de milhares de vítimas e identificar exemplos de abusos cometidos contra detentos sem nenhum tipo de prova. Além disso, essa verdade é revelada não somente por aqueles que cometeram crimes de assassinato e tortura, mas também por autores intelectuais que davam autoridade política e operacional para esses crimes. ${ }^{12}$

\section{CONCLUSÃO}

Neste artigo tentou-se demonstrar o relevante papel que a Justiça Transicional teve na África do Sul após o regime do apartheid. Levando em consideração que a maior preocupação desse tipo de Justiça é tratar das violações de Direitos Humanos, a África do Sul constitui-se um bom caso de análise, pois sofreu com esse tipo de violação desde a época da sua colonização.

Conclui-se que, apesar do grande desafio enfrentado pela Comissão de Verdade e Reconciliação, a África do Sul pode ser considerada um exemplo bem sucedido da atuação da Justiça Transicional. Além disso, pode-se afirmar que seu trabalho contribuiu para

\footnotetext{
${ }^{9} \mathrm{ZYL}$, Paul Van. Dilemmas of Transitional Justice: The case of South Africa's Truth and Reconciliation Commission. Journal of Internations Affairs, Sprig 1999, 52, $\mathrm{n}^{\circ} 2$. The Trustees of Columbia University in the City of New York. pp.655-656.

${ }^{10}$ Ibidem. p. 655.

${ }^{11}$ Ibidem. p. 656.

${ }^{12}$ Ibidem. pp. 657-658.
} 
consolidação da democracia desse país, transformando-o no país mais desenvolvido do continente africano.

Depois de ter passado anos vivendo em um regime segregacionista, a população negra encontrou na Comissão de Verdade e Reconciliação uma forma de lidar com as atrocidades do passado. A partir dela a verdade era revelada e passava-se a conhecer os verdadeiros culpados. Em troca disso, os violadores não tinham seus direitos civis suprimidos e podiam fazer parte novamente da comunidade sul-africana, mas agora conscientes do erro que tinham cometido. As vítimas seriam de alguma forma compensadas para a partir daí se construir uma nova África do Sul com novas instituições, novas estruturas e uma nova sociedade única. Isso ajudou a acabar com toda a insegurança e medo vivido pela população, principalmente no período do apartheid.

O sucesso da Comissão de Verdade e Reconciliação foi estabelecido por várias características que podem ser tomadas de exemplo por muitos países que estão em fase de transição.

O fato de o país ter passado por uma transição pactuada teve pontos positivos, principalmente no que diz respeito à demonstração do uso de conceitos democráticos. A transição para democracia não foi realizada de forma revolucionária, mas sim através de negociações entre o antigo e o novo governo, diante da total fiscalização da sociedade civil.

A ênfase na reconciliação e na idéia de união da população foi um dos traços marcantes. Não se esperava a punição e a vingança, mas sim o reconhecimento pleno da verdade para a reconstrução de uma nova África do Sul democrática. Ademais, a iniciativa de transformar a sociedade sofrida com tantas violações de Direitos Humanos partiu do próprio Estado. A África do Sul não esperou nenhuma intervenção externa para tratar de seus problemas.

Uma outra característica inovadora e essencial para seu pleno desenvolvimento tange a questão da anistia. $\mathrm{O}$ fato de ser concedida somente a certos crimes e de ser individual demonstrava à sociedade que as maiores violações não estavam acima da lei. A exigência da plena revelação podia ser representada como uma prestação de conta e comprometimento em respeito dessa.

Contudo, mesmo depois do término do trabalho da Comissão não se acredita que a África do Sul está com suas bases democráticas totalmente fundamentadas, principalmente no que diz respeito à proteção dos Direitos Humanos. Seu trabalho significa só o início da construção de uma cultura de Direitos Humanos. Sua responsabilidade agora foi divida entre o governo e a sociedade civil. A partir do trabalho conjunto é que o futuro da nação sul-africana tem que ser desenvolvida. E esse deve ser fundamentado no reconhecimento dos Direito Humanos, da democracia e da coexistência pacífica.

Sendo assim acredita-se poder construir um novo país. De um lado existe o governo consciente do seu papel para tratar principalmente de aspectos conjunturais que ainda foram herdados do período do apartheid, como as divisões das comunidades e problemas de infraestrutura. Em contrapartida, encontra-se do outro lado a sociedade civil, agora também consciente do poder da sua participação em todas as esferas governamentais pronta para agir e exigir seus direitos. Assim está sendo construída uma nova África do Sul. E esse modelo de Justiça que proporcionou esse desenvolvimento está servindo de exemplo para muitos países. Prova disso está no fato que desde a publicação do seu relatório final, em 1998, muitos comissários que trabalharam na Comissão de Verdade e Reconciliação, tem sido convidados para trabalhar em outros países que estão em fase de transição. 


\section{REFERÊNCIAS BIBLIOGRÁFICAS}

BORAINE, Alex. A Country Unmasked: Inside South Africa's Truth and Reconciliation Commission. Oxford University Press. 2000.

BRONWYN, Leeban. Restorative Justice for Political Transitions: Lessons from the South Africa Truth and Reconciliation Commission. Contemporary Justice Review.Volume 4. 2001.

CALL,Charles T. Is Transitional Justice Really Just? Journaul of World Affairs. Volume 11. 2004.

CROCKER, David. Truth Commissions, Transitional Justice and Civil Society. In Robert I. Rotberg e Dennis Thompson. Truth v. Justice: The Morality of Truth Commissions. Priceton University, 2000.

GREENAWALT, Kent. Amnesty's Justice. In: Robert I. Rotberg e Dennis Thompson. Truth v. Justice: The Morality of Truth Commission. Princeton University Press. 2000.

OSIEL, J.Mark. Manking public memory, publicly. In: Human Rights in Political Transitions: Gettysburg to Bosnia. Zone Books, New York, 1999.

RUTI, G. Teitel. Transitional Justice. New York: Oxford University Press, 2000.

TUCKER, Aviezer. Paranoids may be persecuted: post-totalitarian retroactive justice. Columbia University. New York,1999.

ZYL, Paul Van. Dilemmas of Transitional Justice: The case of South Africa's Truth and Reconciliation Commission. Journal of Internations Affairs, Sprig 1999, 52, $\mathrm{n}^{\mathrm{o}} 2$. The Trustees of Columbia University in the City of New York. 